\title{
Rendimento da pimenta cayenne em função de diferentes tensões de água no solo
}

\author{
Elvis M. de C. Lima ${ }^{1}$, Jacinto de A. Carvalho ${ }^{1}$, Fátima C. Rezende ${ }^{1}$, \\ Michael S. Thebaldi ${ }^{1}$ \& Rafael F. Gatto ${ }^{1}$
}

\begin{abstract}
RESUMO
Objetivou-se, neste trabalho, avaliar as tensões de água no solo em duas fases fenológicas (vegetativa e reprodutiva) da cultura da pimenta Cayenne, cultivada em ambiente protegido e irrigada por gotejamento. Foram instalados dois experimentos utilizando-se um delineamento inteiramente casualizado cujos tratamentos foram definidos por quatro tensões de água no solo (20, 40, 60 e 120 kPa) e quatro repetições. Os maiores valores de massa média de frutos por planta foram obtidos para a tensão de $20 \mathrm{kPa}$, sendo 1936,83 e 2091,59 g por planta e os coeficientes de rendimento obtidos foram 0,81 e 1,01, para as fases vegetativa e reprodutiva, respectivamente. Com base nos resultados apresentados concluiu-se que: a produtividade da cultura apresentou comportamento inversamente proporcional à tensão de água no solo e a tensão de $20 \mathrm{kPa}$ mostrou-se mais adequada para promover as irrigações nas fases estudadas. Os coeficientes de rendimento identificaram a fase reprodutiva como a mais sensível ao deficit hídrico.
\end{abstract}

Palavras-chave: manejo de irrigação, produtividade, Capsicum frutensces

\section{Yield of Cayenne pepper as a function of different soil water tensions}

\begin{abstract}
This study aimed to evaluate the effect of different soil water tensions at different phenological stages (vegetative and reproductive) on Cayenne pepper cultivated in greenhouse and with drip irrigation. A completely randomized design was used, using four soil water tensions (20, 40, 60 e $120 \mathrm{kPa})$ as treatments with four replications, in two experiments (1 e 2), related to the phenological stages (vegetative and reproductive), respectively. The higher values of fruits mean weight per plant were obtained with $20 \mathrm{kPa}$ soil water tension, being 1,936.83 and 2,091.59 g plant $^{-1}$ and the yield coefficients obtained were 0.81 and 1.01, for vegetative and reproductive stages, respectively. It was concluded that the crop yield presented inversely proportional behavior to the soil water tension, and the $20 \mathrm{kPa}$ tension showed most appropriate to promote the irrigation on the studied stages. The yield coefficients identified the reproductive stage as the most sensitive to the water stress.
\end{abstract}

Key words: irrigation management, productivity, Capsicum frutensces 


\section{INTRODUÇÃO}

As pimentas do gênero Capsicum pertencem à família das solanáceas, a mesma do tomate e da berinjela e são conhecidas por apresentarem um grau de ardência mais elevado do que as pimentas de outros gêneros, como a pimenta-do-reino.

No Brasil, as pimentas são produzidas principalmente nos estados de Minas Gerais, Goiás, São Paulo e Rio Grande do Sul, podendo atingir produtividades médias entre 10 e $30 \mathrm{tha}^{-1}$, dependendo do seu tipo, sendo normalmente comercializadas in natura e em forma de molhos e conservas (Reifschneider \& Ribeiro, 2008).

A irrigação, entre outras técnicas, como o sistema de cultivo e o manejo da irrigação, tem sido determinante para o rendimento satisfatório da pimenteira, sobretudo nas regiões Sul, Sudeste, Centro Oeste e Nordeste do país. Segundo Qiu et al. (2011) o gotejamento é um sistema de irrigação eficaz para o cultivo de pimenta em casas de vegetação devido, sobremaneira, à economia no consumo de água e por apresentar maiores produtividades de vez este ambiente permite um aproveitamento melhor dos recursos de produção (nutrientes, luz e $\mathrm{CO}_{2}$ ) resultando em precocidade de produção. Além disto, a necessidade hídrica (irrigação) é menor em virtude principalmente da redução da velocidade do vento e da atenuação da radiação solar direta incidente (Klar \& Jadosky, 2004).

A necessidade de se conhecer a quantidade de água ideal a ser aplicada no momento certo, motivou a realização de estudos, com diferentes cultivares de pimenta.

Estudando lâminas de reposição de água na cultura da pimenta, Tabasco cv. McIlhenny, em condições de campo Azevedo et al. (2005) obtiveram lâminas variando entre 684 e $1080 \mathrm{~mm}$, para os tratamentos de 40 e $120 \%$ da evaporação do tanque classe $\mathrm{A}$ (ECA) respectivamente e concluíram que a maior produtividade ocorreu para a lâmina de reposição correspondente ao tratamento de $120 \%$ da (ECA).

Diferentes práticas de economia de água de irrigação foram estudadas por Guang-Cheng et al. (2010) na produção da pimenta Zao feng. Os autores observaram redução na massa fresca total de frutos de 39,24 e 27,44\% entre os tratamentos aplicados, ou seja, metade da lâmina de reposição era aplicada simultaneamente em ambos os lados das raizes ou metade era aplicada de forma alternada, respectivamente, quando comparados ao tratamento com lâmina de reposição integral.

Marinho (2011) avaliou a irrigação plena e deficitária sobre a produção da pimenteira $\mathrm{cv}$. Tabasco em casas de vegetação, aplicando lâminas de irrigação equivalentes a 40 , 60,80 e $100 \%$ da evapotranspiração da cultura. Os tratamentos foram iniciados em diferentes épocas, aos 39 e aos 59 dias após transplantio (DAT). Verificou-se que o deficit hídrico influenciou significativamente o peso médio por planta $(548,61$; 598,$27 ; 647,93 ; 697,59 \mathrm{~g}$ ) respectivamente, quando iniciado aos 39 dias e o número de frutos por planta em ambas as épocas de iniciação $(888,47 ; 1090,95 ; 1293,43 ; 1495,91$ frutos) na primeira época e $(835,42 ; 1041,9 ; 1293,43 ; 1495,91$ frutos $)$ na segunda época, respectivamente.

$\mathrm{O}$ efeito do deficit hídrico sobre a produção de diferentes culturas cultivadas em casas de vegetação e em condições de campo, tem sido estudado por alguns autores (Santana et al., 2004; Dorji et al., 2005; Gonzalez-Dugo et al., 2007; Gadissa \& Chemeda, 2009; Bilibio et al., 2010; Ayas et al., 2011 e Oliveira et al., 2011).

Se manejada adequadamente, a irrigação possibilita a oferta de pimenta durante todo o ciclo produtivo, desde que seja cultivada em casas de vegetação; entretanto, para esta cultura são necessários maiores estudos sobre o manejo da irrigação.

O presente estudo foi realizado em casa de vegetação para evitar a interferência pela chuva e para minimizar os efeitos adversos do clima sobre a resposta das plantas, com o objetivo de avaliar as tensões de água no solo em duas fases fenológicas (vegetativa e reprodutiva) da cultura da pimenta Cayenne e determinar o momento mais adequado para se iniciar as irrigações.

\section{Material e Métodos}

Dois experimentos foram desenvolvidos em casa de vegetação em uma área experimental da Universidade Federal de Lavras, Lavras, MG, entre os meses de setembro de 2011 e abril de 2012. O município está localizado a $918 \mathrm{~m}$ de altitude, $21^{\circ} 14^{\prime}$ de latitude Sul e $45^{\circ} 00^{\prime}$ de Longitude Oeste. O clima é do tipo Cwa de acordo com a classificação de Köppen e caracterizado por temperatura média anual do ar de $19,4{ }^{\circ} \mathrm{C}$, umidade relativa média do ar de $76,2 \%$ e precipitação 1529,7 mm (Dantas et al., 2007).

O monitoramento máximo e o mínimo das temperaturas e das umidades relativas do ar foram realizados com auxílio de termohigrômetros digitais, instalados no interior das casas de vegetação a $2 \mathrm{~m}$ de altura do solo. As leituras foram realizadas diariamente, às $9 \mathrm{e} 17 \mathrm{~h}$.

O estudo se constituiu dos experimentos 1 e 2 , nos quais as plantas foram submetidas a tensões de água no solo. Em ambos os experimentos foi utilizado o delineamento inteiramente casualizado, com quatro tratamentos definidos pelas tensões de água no solo de 20, 40, 60 e $120 \mathrm{kPa}$; as unidades experimentais (tratamentos) foram constituídas de três plantas espaçadas 0,6 $\mathrm{m}$ entre plantas e $1,0 \mathrm{~m}$ entre fileiras, com quatro repetições por tratamento.

Foi utilizada, para condução dos experimentos, a espécie (Capsicum frutensces) cv. Cayenne; as mudas foram produzidas em bandejas de 128 células em casa de vegetação (semeadas dia 10/07/2011) e transplantadas no dia 24/09/2011, quando as mudas atingiram de 10 a $15 \mathrm{~cm}$ de altura.

O solo da área experimental, constituído de $18 \%$ de areia, $21 \%$ de silte e $61 \%$ de argila, de textura muito argilosa, foi classificado como Latossolo Vermelho distroférrico conforme EMBRAPA (2006). A equação de retenção de água do solo foi determinada no Laboratório de Relação Água-Solo-Planta do Departamento de Engenharia da UFLA. Foram coletadas amostras indeformadas em cilindros de diâmetro interno médio $34,86 \mathrm{~mm}$ e altura média de $28,53 \mathrm{~mm}$, na camada de $0-0,30$ $\mathrm{m}$ de profundidade. Levando em consideração os dados de umidade obtidos em função das tensões analisadas, gerou-se a equação de retenção de água no solo, Eq.1. $\mathrm{O}$ ajuste foi obtido através do software SWRC desenvolvido por Dourado Neto 
et al. (2000) conforme os parâmetros empíricos propostos por Genuchten (1980).

$$
\theta=0,236+\left(\frac{0,418}{\left[1+(0,377 \cdot|\Psi|)^{1,7902}\right]^{0,4414}}\right)
$$

em que:

$\theta \quad$ - umidade com base em volume, $\mathrm{cm}^{3} \mathrm{~cm}^{-3}$

$\Psi \quad$ - potencial de água no solo, $\mathrm{kPa}$

As adubações foram realizadas com base nas análises de fertilidade do solo, de acordo a recomendação de Gomes et al. (1999).

A quantidade de adubo aplicado por planta foi diluída em $100 \mathrm{~mL}$ e aplicada manualmente em cada planta; a época de aplicação dos nutrientes e suas respectivas dosagens e fontes estão apresentados na Tabela 1.

Tabela 1. Épocas de aplicação, dosagens e fontes dos nutrientes utilizados nos estudos

\begin{tabular}{|c|c|c|c|c|}
\hline \multirow{2}{*}{ Adubação } & \multirow{2}{*}{$\begin{array}{c}\text { Épocas } \\
\text { semanas }\end{array}$} & \multicolumn{3}{|c|}{ Nutrientes $\left(\mathrm{kg} \mathrm{ha}^{-1}\right)$} \\
\hline & & $\mathbf{N}$ & $\mathrm{P}_{2} \mathrm{O}_{5}$ & $\mathrm{~K}_{2} \mathrm{O}$ \\
\hline \multirow[t]{2}{*}{ Plantio } & & 0 & 300 & 80 \\
\hline & $1^{\mathrm{a}} \mathrm{a} 4^{\mathrm{a}}$ & 20 & 60 & 15 \\
\hline \multirow{4}{*}{ Coberturas } & $5^{\mathrm{a}}$ a $8^{\mathrm{a}}$ & 40 & 30 & 25 \\
\hline & $9^{\mathrm{a}} \mathrm{a} 14^{\mathrm{a}}$ & 60 & 10 & 50 \\
\hline & Após $15^{\mathrm{a}}$ & 40 & 0 & 70 \\
\hline & Total & 160 & 400 & 240 \\
\hline Fertilizantes & & Uréia & Super triplo & Sulfato de K \\
\hline utilizados & & MAP & MAP & Cloreto de K \\
\hline
\end{tabular}

O controle periódico das plantas daninhas foi realizado por meio de capinas, durante o ciclo da cultura, e os tratamentos fitossanitários realizados de forma preventiva e curativa a fim de se evitar e eliminar pragas e doenças. As pimenteiras foram conduzidas sem poda; contudo, a partir dos 20 dias após transplantio (DAT) foram retiradas todas as brotações e flores abaixo da primeira bifurcação; o tutoramento das plantas foi realizado com o uso de fitilho de nylon e estacas de madeira.

Iniciou-se a colheita aos 74 dias após transplantio realizando-se semanalmente e se adotando, como critério, a retirada de frutos totalmente maduros, ou seja, coloração avermelhada, com término aos 195 DAT.

O manejo da irrigação foi realizado a partir da leitura das tensões nos tensiômetros instalados em unidades experimentais, com as tensões de 20, 40 e $60 \mathrm{kPa}$ e sensores de matriz granular (Watermark ${ }^{\circledR}$ ) instalados em unidades experimentais para a tensão de $120 \mathrm{kPa}$, ambos instalados a $0,15 \mathrm{~m}$ de profundidade. Buscou-se, em todas as irrigações, elevar a umidade do solo à condição de capacidade de campo, ou seja, umidade correspondente à tensão de $10 \mathrm{kPa}$ para o solo estudado.

O momento de irrigar foi estabelecido quando a média das leituras de pelo menos três tensiômetros ou sensores de matriz granular atingisse a tensão estabelecida para cada tratamento. As tensões de água no solo para o manejo realizado com tensiômetros foram corrigidas conforme Eq. 2.

$$
\psi=\mathrm{L}+0,098 \cdot \mathrm{C}
$$

em que:

$\psi \quad$ - potencial matricial da água no solo, $\mathrm{kPa}$

$\mathrm{L}$ - leitura do tensímetro digital, $\mathrm{kPa}$

C - comprimento do tensiometro, $\mathrm{cm}$

O volume de água aplicado por planta foi obtido considerando-se o volume de solo ocupado por planta (o produto da área ocupada por planta $0,6 \mathrm{~m}^{2}$, pela profundidade efetiva do sistema radicular $0,3 \mathrm{~m}$ ), do coeficiente de uniformidade de distribuição (CUD) de $97 \%$ e da eficiência do sistema de irrigação $95 \%$. O tempo de funcionamento da irrigação em cada tratamento foi determinado a partir da relação entre o volume de água aplicado em cada tratamento e a vazão média dos emissores Eq. 3.

$$
\mathrm{Ti}=\frac{\mathrm{Vol}_{\text {agua }}}{\mathrm{e} \cdot \mathrm{q}_{\mathrm{e}}}
$$

em que:

Ti - tempo de irrigação em cada tratamento, $h$

$\mathrm{Vol}_{\text {agua }}$ - volume de água determinado para cada tratamento, $\mathrm{L}$

qe - vazão média dos emissores, $\mathrm{L} \mathrm{h}^{-1}$

e - número de emissores

Durante os 15 dias após transplantio todos os tratamentos foram submetidos às mesmas lâminas de irrigação, de maneira a garantir o pegamento das mudas; posteriormente, foram aplicados os tratamentos no experimento 1 , referente à fase vegetativa, que compreendeu o período entre o transplantio e o momento no qual $50 \%$ das plantas apresentaram flores; após este período as plantas foram submetidas somente à tensão de $20 \mathrm{kPa}$; da mesma forma foi avaliado o efeito dos tratamentos no experimento 2 , durante a fase reprodutiva, que compreendeu o período entre o final da fase vegetativa e a colheita final.

As avaliações foram realizadas para todas as plantas dos experimentos, sendo três plantas por unidade experimental; em cada colheita os frutos sem danos físicos foram pesados em balança digital com precisão de $1 \mathrm{~g}$ e contados; em seguida, eram medidos individualmente utilizando-se um paquímetro digital com precisão de $0,05 \mathrm{~mm}$; a partir dessas informações foram analisados a massa média dos frutos, o número médio de frutos por planta, a massa média de frutos por planta, o diâmetro e o comprimento médios dos frutos.

A quantificação do efeito do déficit hídrico sobre a produtividade dos frutos foi determinada pela relação entre a redução relativa da produtividade e a redução relativa da lâmina de irrigação aplicada dada pelo coeficiente de resposta ky conforme Eq. 4 (Doorenbos \& Kassan, 1994).

$$
\left(1-\frac{\mathrm{Yr}}{\mathrm{Ym}}\right)=\left(1-\frac{\mathrm{Lr}}{\mathrm{Lm}}\right)
$$

em que:

Yr - produtividade real obtida

$\mathrm{Ym}$ - produtividade potencial obtida

Ky - coeficiente de resposta da cultura 
Lr - lâmina de irrigação real, $\mathrm{mm}$

Lm - lâmina de irrigação potencial, mm

Foram consideradas a produtividade potencial (Ym) e a lâmina de irrigação potencial (Lm) aquelas obtidas dos tratamentos correspondentes à tensão de $20 \mathrm{kPa}$ e a produtividade real (Yr) e a lâmina de irrigação real (Lr) as obtidas dos diferentes tratamentos. Obteve-se o coeficiente de rendimento Ky para a fase vegetativa considerando-se apenas as lâminas aplicadas a partir da diferenciação dos tratamentos, ou seja, dos 15 DAT aos 50 DAT.

Os dados amostrados foram submetidos à análise de variância com regressão polinomial com níveis de significância de 0,01 e 0,05, com auxílio do software Sisvar 5.0 (Ferreira, 2011).

\section{Resultados E Discussão}

No período de condução do experimento a temperatura média do ar foi de $23,9^{\circ} \mathrm{C}$, a temperatura mínima ficou entre 9,3 e $23{ }^{\circ} \mathrm{C}$ e a temperatura máxima esteve entre 16,7 e $40,8^{\circ} \mathrm{C}$ (Figura 1A) com média mínima de $16,5^{\circ} \mathrm{C}$ e média máxima de $31,5^{\circ} \mathrm{C}$. Segundo Pinto et al. (2006) as médias de temperatura ideais para um bom desenvolvimento da pimenteira se situam entre 21 e $30^{\circ} \mathrm{C}$ e a média das temperaturas mínima e máxima de 18 e $35^{\circ} \mathrm{C}$, respectivamente. Portanto, a temperatura média observada se encontra dentro da faixa considerada ideal e os valores de temperatura média mínima e média máxima, próximos aos valores recomendados.

Os valores de umidade relativa do ar apresentados na Figura 1B foram coletados para o mesmo período experimental. A umidade relativa média observada foi de $66,2 \%$ próxima ao valor de $80 \%$, considerado ideal ao cultivo sendo que a umidade relativa mínima variou entre 20 e $80 \%$ e a umidade relativa máxima entre 88 e $99 \%$. O valor obtido de umidade relativa média foi de $66,2 \%$ (Crisóstomo, 2006).

A Tabela 2 exibe o resumo da análise de variância realizada para a massa média dos frutos, número médio de frutos por planta, massa média de frutos por plantas, diâmetro e comprimento médios dos frutos em função das tensões de água no solo, durante o experimento 1 .

Verificou-se, pela análise de variância a 0,05 e a 0,01 de probabilidade, que as tensões de água no solo aplicadas interferiram significativamente no número médio de frutos por planta e na massa média de fruto por planta, respectivamente, $\mathrm{o}$ que não ocorreu para a massa média, diâmetro e comprimento médios dos frutos.

A Figura 2A ilustra o comportamento do número médio de frutos por planta em função das tensões de água no solo.
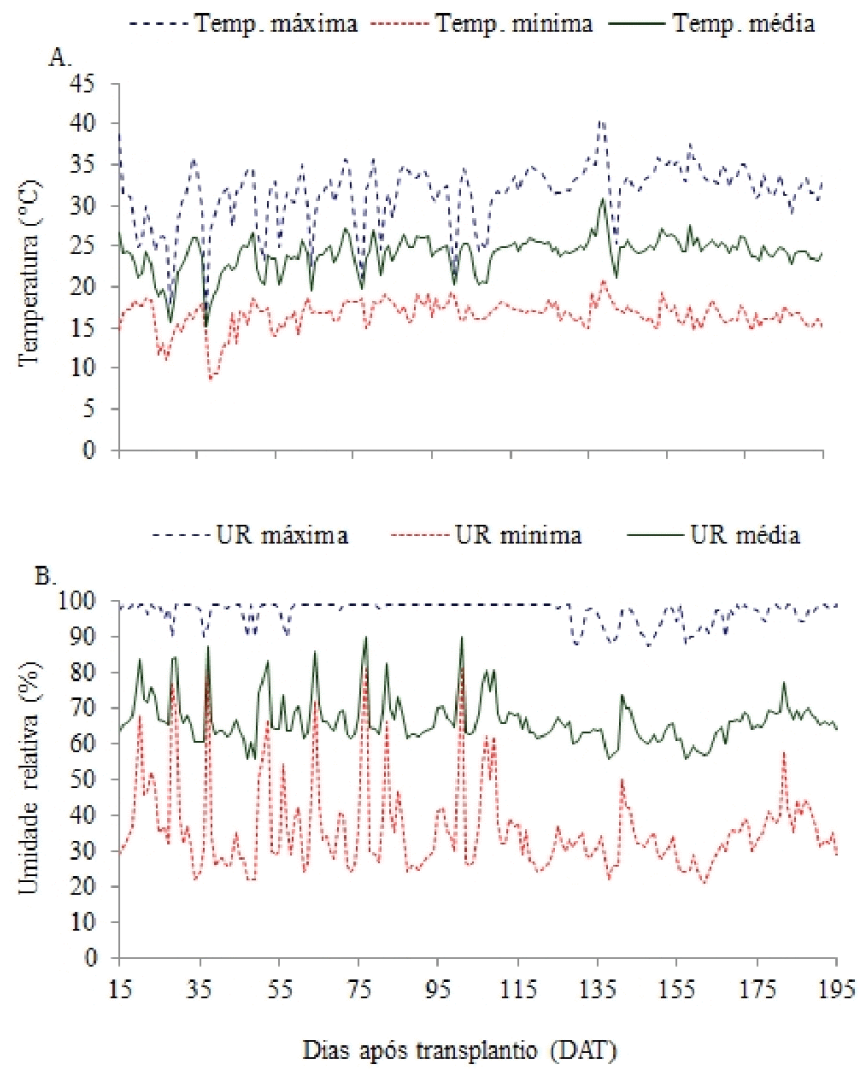

Figura 1. Temperatura máxima, mínima e média $(A)$ e umidade relativa máxima, mínima e média (B), observadas durante a execução do experimento

Observou-se tendência de redução linear no número médio de frutos por planta, em função do aumento da tensão de água no solo.

Comportamento semelhante ao deste trabalho foi apresentado por Santana et al. (2004) em que os tratamentos referentes às tensões de água no solo $(10,30,50$ e $60 \mathrm{kPa})$ influenciaram significativamente tanto a massa média de frutos por planta quanto o número total de frutos por planta, apresentando redução dessas variáveis com o aumento das tensões de água no solo. Em trabalho realizado com a cultura do pepino japonês, em casa de vegetação, Oliveira et al. (2011) verificaram que o número e a massa de frutos por planta, da mesma forma, foram reduzidos com o aumento das tensões de água no solo utilizadas como tratamento $(15,30,60$ e $120 \mathrm{kPa})$.

A diminuição do número de frutos com o acréscimo da tensão de água no solo pode ser explicada pelo distúrbio no desenvolvimento das plantas como redução de área foliar, provocados pelo déficit de água no solo, principais causadores de estresse nas culturas (Klar \& Jadoski, 2002).

Tabela 2. Análise de variância para a massa média dos frutos (MMF), número médio de frutos por planta (NF), massa média de frutos por planta (MFP), diâmetro (DF) e comprimento (CF) médios dos frutos, em função dos tratamentos no experimento 1

\begin{tabular}{ccccccc}
\hline \multirow{2}{*}{ FV } & GL & \multicolumn{5}{c}{ Quadrado Médio } \\
\cline { 3 - 6 } & 3 & MMF & NF & MFP & DF & $0,0008 \mathrm{~ns}$ \\
Tensão & 12 & $0,40 \mathrm{~ns}$ & $13.072,85^{*}$ & $491.858,42^{* *}$ & $0,0341 \mathrm{~ns}$ \\
Resíduo & 0,33 & $2.343,35$ & $38.273,52$ & 0,0014 & 0,3062 \\
\hline CV (\%) & & 11,76 & 15,73 & 13,06 & 3,20 & 6,16 \\
Média geral & & 4,87 & 307,69 & $1.497,75$ & 1,17 & 8,98 \\
\hline
\end{tabular}

**: Significativo a 0,01 de probabilidade; *: Significativo a 0,05 de probabilidade; ns: Não significativo a 0,05 de probabilidade 

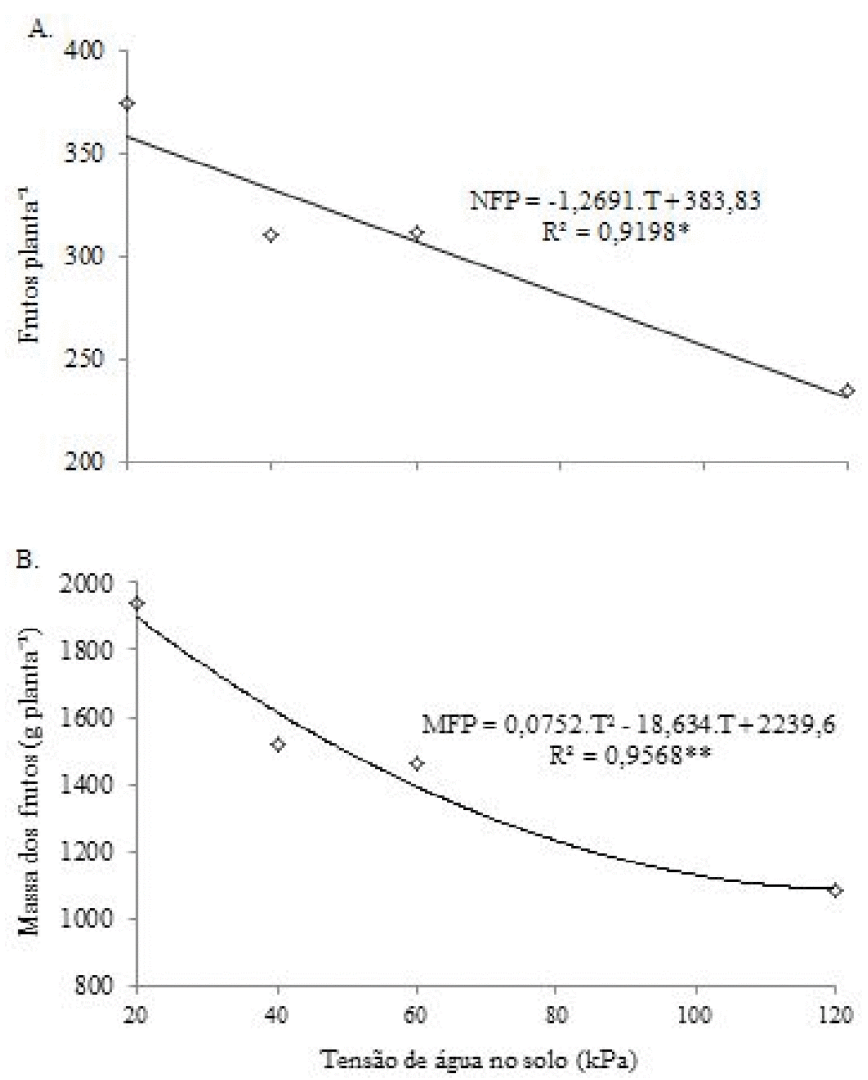

Figura 2. Número médio de frutos por planta (A) e massa média dos frutos por planta (B) em função de tensões de água no solo no experimento 1 fase reprodutiva

A Figura 2B ilustra os dados obtidos de massa média dos frutos por planta, em função dos tratamentos aplicados. Observou-se tendência de redução polinomial quadrática na massa média de frutos por planta, em função do aumento da tensão de água no solo com coeficiente de determinação $\mathrm{R}^{2}$ de 0,9568 .

Os resultados observados neste trabalho se apresentaram semelhantes aos obtidos por Marinho (2011) ao verificar tendência à redução da produtividade da pimenteira com o aumento do déficit hídrico, sendo o modelo linear a $1 \%$ de probabilidade o que melhor se ajustou. Segundo o autor, o déficit hídrico durante a fase vegetativa provocou, em determinados níveis, um estresse hídrico de moderado a severo nas plantas.

Em contrapartida, Bilibio et al. (2010) estudaram o efeito do incremento do deficit hídrico durante a fase de desenvolvimento da cultura da berinjela e verificaram que os tratamentos não diferiram entre si para um nível de significância de 0,05 , segundo os quais os resultados podem ser explicados pelo curto período da fase vegetativa da cultura, que foi de 24 dias.

Na Tabela 3 está representado o resumo da análise de variância realizada para a massa média dos frutos, número de frutos por planta, massa de frutos por plantas, diâmetro e comprimento médios dos frutos em função das tensões de água no solo, durante o experimento 2 (fase reprodutiva).

Constatou-se, a 0,01 e 0,05 de probabilidade, que as tensões de água no solo aplicadas interferiram significativamente na massa média de fruto por planta e na massa média dos frutos, o que não ocorreu para o número de frutos por planta, diâmetro e comprimento médio dos frutos, que não apresentaram diferença significativa nos resultados.

A Figura 3A representa o comportamento da massa média dos frutos em função das tensões de água no solo. Observouse redução linear nos valores de massa média dos frutos em função dos tratamentos.
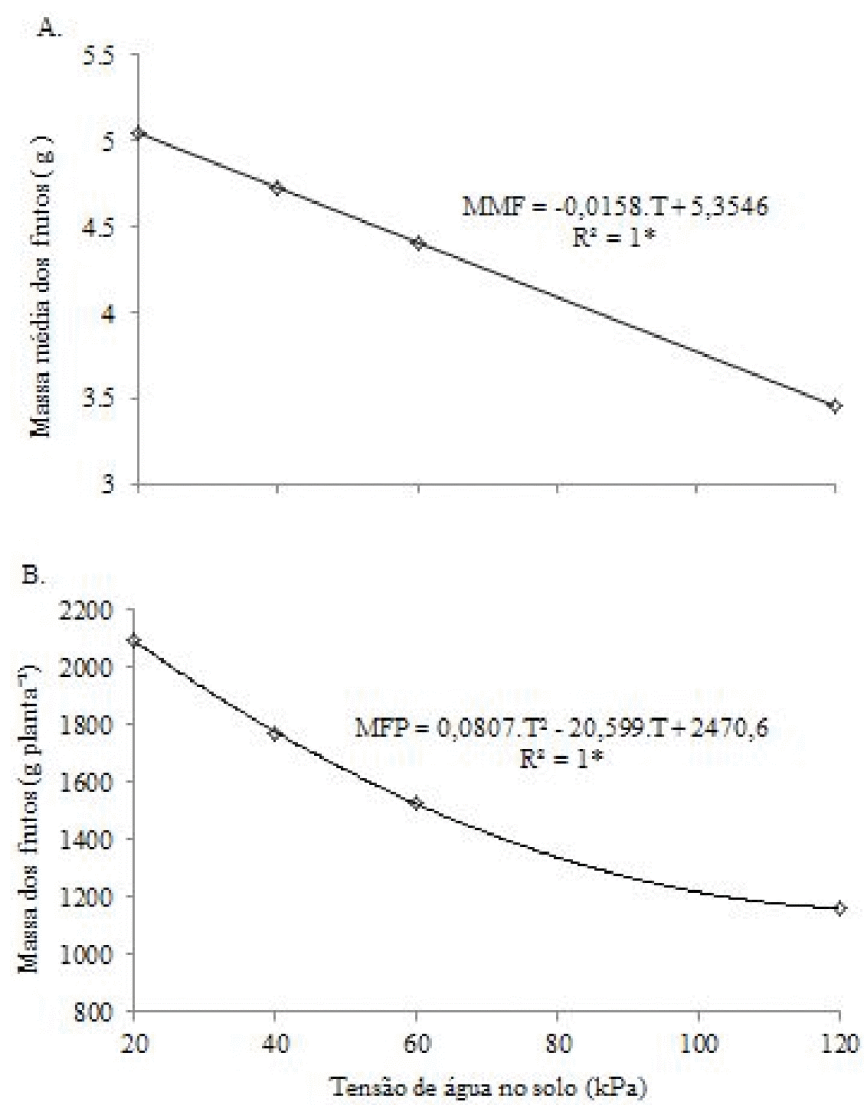

Figura 3. Massa média dos frutos (A) e massa média dos frutos por planta (B) em função de tensões de água no solo no experimento 2 fase reprodutiva

Tabela 3. Análise de variância para a massa média dos frutos (MMF), número médio de frutos por planta (NF) emassa média de frutos por planta (MFP), diâmetro (DF) e comprimento (CF) médio dos frutos em função dos tratamentos no experimento 2

\begin{tabular}{|c|c|c|c|c|c|c|}
\hline \multirow{2}{*}{ FV } & \multirow{2}{*}{ GL } & \multicolumn{5}{|c|}{ Quadrado Médio } \\
\hline & & MMF & NF & MFP & DF & CF \\
\hline Resíduo & 12 & 0,28 & $2.362,89$ & $20.211,98$ & 0,0029 & 0,38 \\
\hline Média geral & & 4,41 & 371,31 & $1.638,10$ & 1,14 & 8,92 \\
\hline
\end{tabular}

**: Significativo a 0,01 de probabilidade; ns: Não Significativo a 0,05 de probabilidade 
Comportamento semelhante obtiveram Azevedo et al. (2005) quando estudaram os percentuais de reposição de água $(40,60,80,100,120 \%)$ da evaporação do tanque classe A sobre as características de rendimento da cultura da pimenta cv. Tabasco e observaram tendência a decréscimo do peso médio dos frutos em função da diminuição das lâminas de água aplicadas.

Marinho (2011) diferente do presente estudo, não obteve diferença significativa da massa média dos frutos da pimenta cv. Tabasco quando submetida a diferentes níveis de déficit hídrico (40, 60, 80 e 100\%) da evapotranspiração da cultura, iniciados a partir da sua fase reprodutiva.

A Figura 3B representa os dados obtidos de massa média dos frutos por planta para cada tensão de água no solo, constatandose redução polinomial quadrática na massa média dos frutos por planta em função do aumento da tensão de água no solo.

Resultados semelhantes foram obtidos por Guang-Cheng et al. (2010) estudando o efeito do déficit hídrico imposto durante a fase reprodutiva da pimenta Zao feng; segundo os autores, ambas as técnicas de aplicação da água de irrigação aplicando $50 \%$ da irrigação de referência, ou seja, reposição de água quando o solo atingia a umidade equivalente a $80 \%$ da capacidade de campo, promoveram redução significativa na produtividade.

Apresenta-se, na Figura 4, a queda de rendimento em função do déficit aplicado nas fases vegetativa e reprodutiva da cultura (experimentos 1 e 2); os coeficientes angulares das equações de regressão caracterizaram os coeficientes de rendimento Ky de 0,81 e 1,01 para as fases vegetativa e reprodutiva, respectivamente.

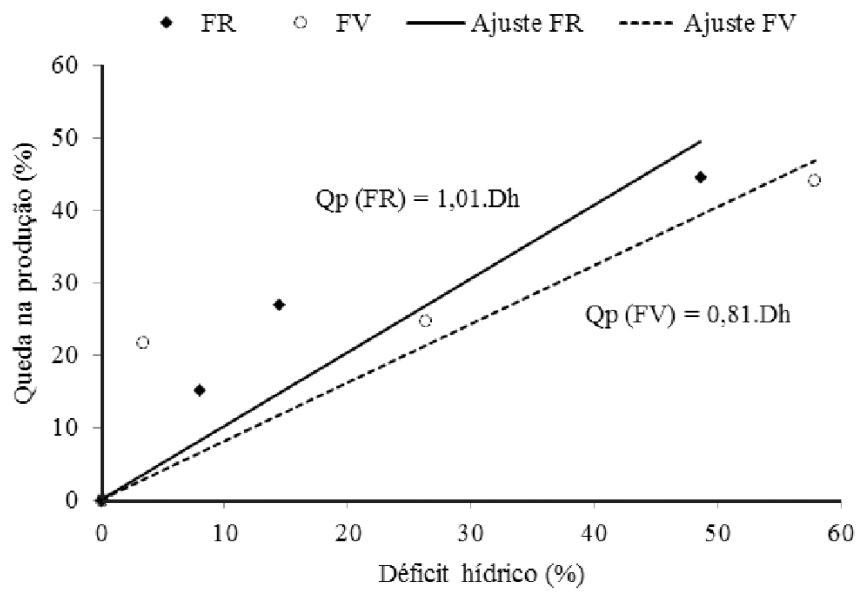

Figura 4. Queda na produção em função do déficit hídrico (Dh) nas fases vegetativa e reprodutiva da pimenta Cayenne

De forma semelhante, Bilibio et al. (2010) identificaram, partindo dos coeficientes de rendimento obtidos, 0,26 e 1,49, para as fases vegetativa e reprodutiva para cultura da berinjela, respectivamente, a fase reprodutiva como a mais sensível ao deficit hídrico.

Em contrapartida, Marinho (2011) observou, avaliando o efeito do deficit hídrico sobre as características de rendimento da pimenta Tabasco McIlhenny, sob condições de ambiente protegido que as plantas quando submetidas ao deficit hídrico desde a fase vegetativa se mostraram mais susceptíveis quando comparadas com as plantas que foram impostas ao déficit hídrico somente a partir da fase de florescimento.

\section{CONCLUSÕES}

1. A produtividade da cultura decresceu com o aumento das tensões aplicadas durante as fases vegetativa e reprodutiva.

2. A tensão de $20 \mathrm{kPa}$ mostrou-se mais adequada para se promover as irrigações em ambas as fases de desenvolvimento da pimenta cv. Cayenne.

3. Os fatores de resposta obtidos foram de 0,81 e 1,01 para as fases vegetativa e reprodutiva, respectivamente, indicando que a fase reprodutiva é mais sensível ao deficit hídrico.

\section{Agradecimentos}

À Coordenação de Aperfeiçoamento de Pessoal de Nível Superior - CAPES; à Fundação de Amparo à Pesquisa do Estado de Minas Gerais - FAPEMIG, e ao Departamento de Engenharia da Universidade Federal de Lavras.

\section{Literatura Citada}

Ayas, S.; Orta, H.; Yazgan, S. Deficit irrigation effects on brocolli (Brassica oleracea L. var.Monet) yeld unheated greenhouse condition. Bulgarian Journal of Agricultural Science, v.17, p.551-559, 2011.

Azevedo, B. M. D.; Chaves, W. P.; Medeiros, F. de M.; Aquino, B. F. de; Bezerra, F. M. L.; Viana, T. V. de A. Rendimento da pimenteira em função de lâminas de irrigação. Revista Ciência Agronômica, v.36, p.268-273, 2005.

Bilibio, C.; Carvalho, J. A.; Rezende, F. C.; Freitas, E. A.; Gomes, L. A. A. Desenvolvimento vegetativo e produtivo da berinjela submetida a diferentes tensões de água no solo. Revista Brasileira de Engenharia Agrícola e Ambiental, v.14, p.730-735, 2010.

Crisóstomo, J. R. Sistemas 3 de produção: Cultivo de pimenta tabasco no Ceará. Fortaleza: Embrapa agroindústria tropical, 2006. 40p. <www.cnpat.embrapa.br/home/dow/index. php?pub/sp 3pdf>. 10 Jan.2012.

Dantas, A. A. A.; Carvalho, L. G.; Ferreira, E. Classificação e tendência climática em Lavras. Revista Ciência e Agrotecnologia,v.31, p.1862-1866, 2007.

Doorenbos, J.; Kassan, A. H. Efeito da água no rendimento das culturas. Campina Grande: UFPB, 1994. 306p.

Dorji, K.;Behboudian, M. H.; Zegbe-Dominguez, J. A. Water relations, growth, yield and fruit quality of hot pepper under deficit irrigation and partial rootzone drying. Scientiae Horticulturae, v.105, p.138-149, 2005.

Dourado Neto, D.; Nielsen, D. R.; Hopmans, J. W.; Reichardt, K.; Bacchi, O. O. S. Software to model soil water retention curves (SWRC, version 3,00). Scientia Agricola, v.57, p.191-192, 2000.

EMBRAPA - Empresa Brasileira de Pesquisa Agropecuária. Centro Nacional de Pesquisa de Solos. Sistema brasileiro de classificação de solos, Brasilia: Embrapa Produção de Informação; Rio de Janeiro: Embrapa solos, 2006. 306p. 
Ferreira, D.F. Sisvar: Um sistema computacional de análise estatística. Revista Ciência e Agrotecnologia, v.35, p.10391042, 2011.

Gadissa, T.; Chemeda, D. Effects of drip irrigation levels andplanting methods on yield and yield components of green pepper (Capsicum annuum, L.) in Bako, Ethiopia. Agricultural Water Management, v.96, p.1673-1678, 2009.

Genuchten, M. T. van. A closed form equation for predicting the hydraulic conductivity of unsaturated soils. Soil Science Society of America Journal, v.44, p.892-898, 1980.

Gomes, L. A. A.; Silva, E. C. D. S.; Faquin, V. Recomendações de adubação para cultivos em ambiente protegido. In: Ribeiro, A. C.; Guimarães, P. T. G.; Alvarez, V. H. Recomendação para usos de corretivos e fertilizantes em Minas Gerais: $5^{\text {a }}$ aproximação. Viçosa: UFV, 1999. Cap.5, p.99-110.

González-Dugo, V.; Orgaz, F.; Fereres, E. Responses of pepper to deficit irrigation for paprika producttion. Scientia Horticulturae, v.114, p.77-82, 2007.

Guang-Cheng, S.; Na, L.; Zhan-Yu, Z.; Shuang-En, Y.; ChangRen, C. Growth, yeld and water use efficiency response of greenhouse-grow hot pepper under timer-space deficit irrigation. Scientia Horticulturae, v.126, p.172-179, 2010.

Klar, A. E.; Jadosky, S. O. Efeitos da irrigação e da cobertura do solo por etileno preto sobre as características morfológicas do pimentão. Revista Irriga,v.7, p.154-167, 2002.
Klar, A. E.; Jadosky, S. O. Irrigation and muching management for sweet pepper crop in protected environment. Revista Irriga, v.9, p.217-224, 2004.

Marinho, L. B. Irrigação plena e com déficit em pimenta cv. Tabasco em ambiente protegido. Piracicaba: ESALQ, 2011.102p. Tese Doutorado

Oliveira, E. C.; Carvalho, J. de A.; Silva, W. G. da; Rezende, F. C.; Almeida, W. F. de.Effects of water deficit in two phenological stages on production of japonese cucumber cultived in greenhouse. Engenharia Agrícola, v.31, p.676686, 2011.

Pinto, M. F.; Puiatti, M.; Caliman, F. R. B.; Moreira, G. R.; Mattos, R. N. Clima, época de semeadura, produção de mudas, plantio e espaçamento na cultura da pimenteira. Informe Agropecuário, v.27, p.40-49, 2006.

Qiu, R.; Kang, S.; Li, F.; Du, T.; Tong, L.; Wang, F.; Chen, R.; Liu, J.; Li, S. Energy partitioning a and evapotranspiration of hot pepper grown e greenhouse with furrow and drip irrigation methods. Scientia Horticulturae, v.129, p.790797, 2011.

Reifschneider, F. J. B.; Ribeiro, C. S. D. Cultivo. In: Ribeiro, C. S. D. Pimentas Capsicum. Brasília: Embrapa Hortaliças, 2008. Cap.1, p.11-14.

Santana, M. J.; Carvalho, J. de A.; Faquin, V.; Queiroz, T. M. de. Produção do pimentão (Capsicum annuum L.) irrigado sob diferentes tensões de água no solo e doses de cálcio. Revista Ciência e Agrotecnologia, v.28, p.1385-1391, 2004. 